\title{
The In-Line placement of EDFA in CWDM/DWDM system for BER comparison at $1540 \mathrm{~nm}$
}

\author{
Tomáš Ivaniga ${ }^{1}$ and Petr Ivaniga ${ }^{2}$ \\ ${ }^{1}$ Department of Electronics and Multimedia Communications, University of Technology Košice, Košice, Slovakia \\ ${ }^{2}$ Department of Information Networks, Faculty of Management Science and Informatics, University of Žilina, Žilina, Slovakia
}

Received 29 May 2018; Accepted 14 September 2019

\begin{abstract}
The continual increase in transfer capacity and speed leads to the continual improvement of fully optical transfer communication systems. The aim of this article is to present the creation of an 8-channel CWDM (Coarse Wavelength Division Multiplex) system (gap spacing of $20 \mathrm{~nm}$ ), where 10 channels, with gaps of $2 \mathrm{~nm}$ are gradually inserted between wavelengths of $1530 \mathrm{~nm}$ to $1550 \mathrm{~nm}$ according to the ITU-T G.694.1 recommendation. This system is evaluated using the BER (Bit Error Rate) of a specific channel operating on a wavelength of $1540 \mathrm{~nm}$. In the topology we used an EDFA (Erbium Doped Fibre Amplifier) placed In-Line at $90 \mathrm{~km}$ with a bit speed of 10 Gbit.s-1. Consequently, in order to overcome the problem of distance, an optical loop with an appropriate EDFA configuration was created. This article presents the basic mathematical description of bit error rate and also deals with the possibility of the incorporation of CWDM and DWDM systems into existing infrastructures.
\end{abstract}

Keywords: BER, CWDM, DWDM, Q-factor

\section{Introduction}

An elementary transfer system generally contains three basic blocks: transmission, transfer and reception. For approximately ninety years after the telephone was invented in 1876 , the main transfer media were pairs of metal cables twisted together [1], [2]. With the advance of computer systems and their ever-increasing data capacity and with the increasing portfolio of telephone options, the metal cables reached their limits. The breakthrough came in 1966 when Hackman and Kao proposed the use of optical fibres as an alternative solution to metal cables [3-5]. The change happened four years later when an OF (Optical Fibre) with an attenuation of less than $20 \mathrm{~dB} \cdot \mathrm{km}^{-1}$ was made. Within seven years the commercial use of $\mathrm{OF}$ in communication networks had begun. During that time attenuation values were decreased to under $1 \mathrm{~dB} \cdot \mathrm{km}^{-1}$ and today optical fibres with the attenuation value under $0.3 \mathrm{~dB} \cdot \mathrm{km}^{-1}$ are accessible. Currently, the problem is not attenuation values but the ever-increasing demand for the increase in transfer speed and the transfer capacity of the already existing systems. The operators of optical communication systems are constantly pressured to raise the system's transfer capacity due to the amount of transferred data. This increase is mostly caused by the popular use of the cloud and multimedia services. Due to this capacity demand, an economical and logically manageable step would be for providers is to oversee a gradual transition to higher transfer speeds - using the existing optical network infrastructure which represents an already sizeable investment [6], [7]. One of the options of how to use optical lines effectively is to employ wavelength multiplexes WDM.

\footnotetext{
*E-mail address: tomas.ivaniga@tuke.sk

ISSN: $1791-2377$ @ 2019 School of Science, HHU. All rights reserved.

doi:10.25103/jestr.125.01
}

By adopting a transfer speed of $10 \mathrm{Gbit}^{-1} \mathrm{~s}^{-1}$ and creating 100 spectral channels using WDM, transfer speeds of up to 1 Tbit. $\mathrm{s}^{-1}$ within one OF could be achieved. When transferring over long distances - of approximately over $100 \mathrm{~km}$ - the signal is weakened (attenuated) and it is necessary to employ optical amplifiers for its subsequent amplification [8], [16]. In such cases the amplifiers used enable a direct amplification of the optical signal - meaning they do no need to convert the optical signal into its electrical form and back again, as is the practise of repeaters [9]. In brief, the length of the optical line without optical amplifiers is dependent on: the transmitting power of the transmitter's laser, the type of OF, the transmitted signal and the sensitivity of the optical detector located in the receiver.

\section{Fusion of CWDM/DWDM}

The fusion of wave multiplexes WDM is implemented mostly to increase the total capacity of the transfer system. This increase of WDM capacity can be reached in several ways not necessarily exclusive of one another [10-12]. The first option is to add more channels to the system, though that would result in the increase of the whole work spectrum which can already be exhausted because the majority of the components operate only within a limited spectrum. The second method is the decrease of gaping between channels, e.g. $100 \mathrm{GHz}, 50 \mathrm{GHz}, 25 \mathrm{GHz}$ to $12.5 \mathrm{GHz}$ [27]. The last solution would be to increase the data speed of individual channels. The co-existence of systems is understood as the incorporation of systems with higher data transfer speeds of its channels (e.g. $40 \mathrm{Gbit}^{-1} \mathrm{~s}^{-1}$ ) into the existing systems with lower data transfer speeds of their channels (e.g. $10 \mathrm{Gbit}^{-1} \mathrm{~s}^{-1}$ ). In the technical terminology such systems could be found 
under "The hybrid transfer systems 10G/40G" or "mix $10 G / 40 G$ ". According to the recommendation ITU-T G.696.1 the majority of fully optical communication systems work with a transfer speed of $10 \mathrm{Gbit}^{-1} \mathrm{~s}^{-1}$ sing NRZ (Non-Return to Zero) with gaping of $50 \mathrm{GHz}$ or $100 \mathrm{GHz}$ [13-15]. Because considerable finances have been devoted to the construction of systems with a transfer speed of $10 \mathrm{Gbit}^{-1} \mathrm{~s}^{-1}$, uprooting the entire system for something newer would be very costly. Therefore, it is logical that the next step for operators regarding how to increase transfer speeds would be to use the already existing infrastructure. It goes without saying that the new system would also be expected to be retroactively compatible. Due to the stated reasons, the $40 \mathrm{Gbit}^{-1}{ }^{-1}$ and $100 \mathrm{Gbit}^{-1} \mathrm{~s}^{-1}$ systems have a number of limitations requiring some attention. They are able to exist within the old infrastructure (fibres of type SMF) without changes to the: dispersion map, resistance to non-linear effects and PMD (Polarization Mode Dispersion), the signal's transition through OADM (Optical Add-Drop Multiplexor), their mutual influencing between $10 \mathrm{Gbit}^{-1}$ and $40 \mathrm{Gbit}^{-\mathrm{s}^{-}}$ $1 / 100 \mathrm{Gbit}^{-1} \mathrm{~s}^{-1}$ and the option of maintaining the $50 \mathrm{GHz}$ gaping. Increasing the transfer speed from $10 \mathrm{Gbit}^{-1}{ }^{-1}$ to $40 \mathrm{Gbit}^{-1} \mathrm{~s}^{-1}$ and more, brings several problems, making the typical solution of the classic amplitude modulation OOKNRZ (On-Off Keying Non-Return to Zero) unusable for this level [16-19]. This is why the systems with greater transfer speed utilise the duobinary modulations (DPSK and DQPSK) and phase modulation PSK (Phase Shift Keying). At the mentioned transit the BER is increased 16 times - caused by the chromatic dispersion, the squaring the speed multiple. The value of chromatic dispersion at the speed of $10 \mathrm{Gbit}^{-1} \mathrm{~s}^{-1}$ is tolerated by NRZ to $1000 \mathrm{ps} / \mathrm{nm} / \mathrm{km}$, whereas for the speed of $40 \mathrm{Gbit}^{-1} \mathrm{~s}^{1}$ it is only $60 \mathrm{ps} / \mathrm{hm} / \mathrm{km}$. That implies that with the increase of transfer speed, dispersion compensation is necessary if not indispensable [20]. The other restriction is the requirement for OSNR which has to be larger by $6 \mathrm{~dB}(10 \mathrm{~dB})$ for the $40 \mathrm{Gbit}^{-1} \mathrm{~s}^{-1}\left(100 \mathrm{Gbit}^{-1} \mathrm{~s}^{-1}\right)$ receiver - if the original BER is to be maintained. Also, the resistance against PMD decreases with the multiplication of speed to the limiting points of 3 ps for $40 \mathrm{Gbit}^{-1} \mathrm{~s}^{-1}$ and $1 \mathrm{ps}$ for $100 \mathrm{Gbit}^{-1} \mathrm{~s}^{-1}$. It is created due to the production imperfections of $\mathrm{OF}$ and it causes delay between polarisation components [21]. Its compensation is not a stochastic process, compared to the chromatic dispersion. OF from before 1994 are unusable for high-speed and high-capacity transfers because of their high values of PMD. It has been proven that the restriction due to PMD and chromatic dispersion is negligible if using a coherent reception with digital signal processing. Also, the

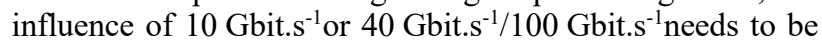
mentioned [22-24]. If the system with a transfer speed of $10 \mathrm{Gbit}^{-1} \mathrm{~S}^{-1}$ OOK-NRZ is merged to a system with a speed of $40 \mathrm{Gbit}^{-1} \mathrm{~s}^{-1}$ using PSK, the $40 \mathrm{Gbit}^{-1} \mathrm{~s}^{-1}$ system will be interfered with XPM (Cross Phase Modulation) - which originates from amplitude modulation. The interaction between transfer systems with $10 \mathrm{Gbit}^{-1} \mathrm{~s}^{-1}$ and $40 \mathrm{Gbit}^{-1} \mathrm{c}^{-1}$ be influenced by a simple change of transfer power or by a correct placing of channels. With appropriate planning for dispersion compensation and by the introduction of RDPS (Residual Dispersion Per Span) these reductions are possible: XPM and FWM (Four Wave Mixing). This is closely connected with choosing a correct type of OF. ITU-T G.652 shows a greater chromatic dispersion than ITU-T G.655 or ITU-T G.653, so it is better to suppress the occurrence of non-linear effects at the output [25]. It has been experimentally discovered that the phase-modulated signals with a higher symbolic speed (e.g. DPSK) have the tendency to be less influenced by XPM than the signals with a lower symbolic speed (e.g. DQPSK) [26]. The other alternative to coexistence is the fusion of CWDM and DWDM systems (in technical terminology marked as " $C W D M / D W D M$ ").

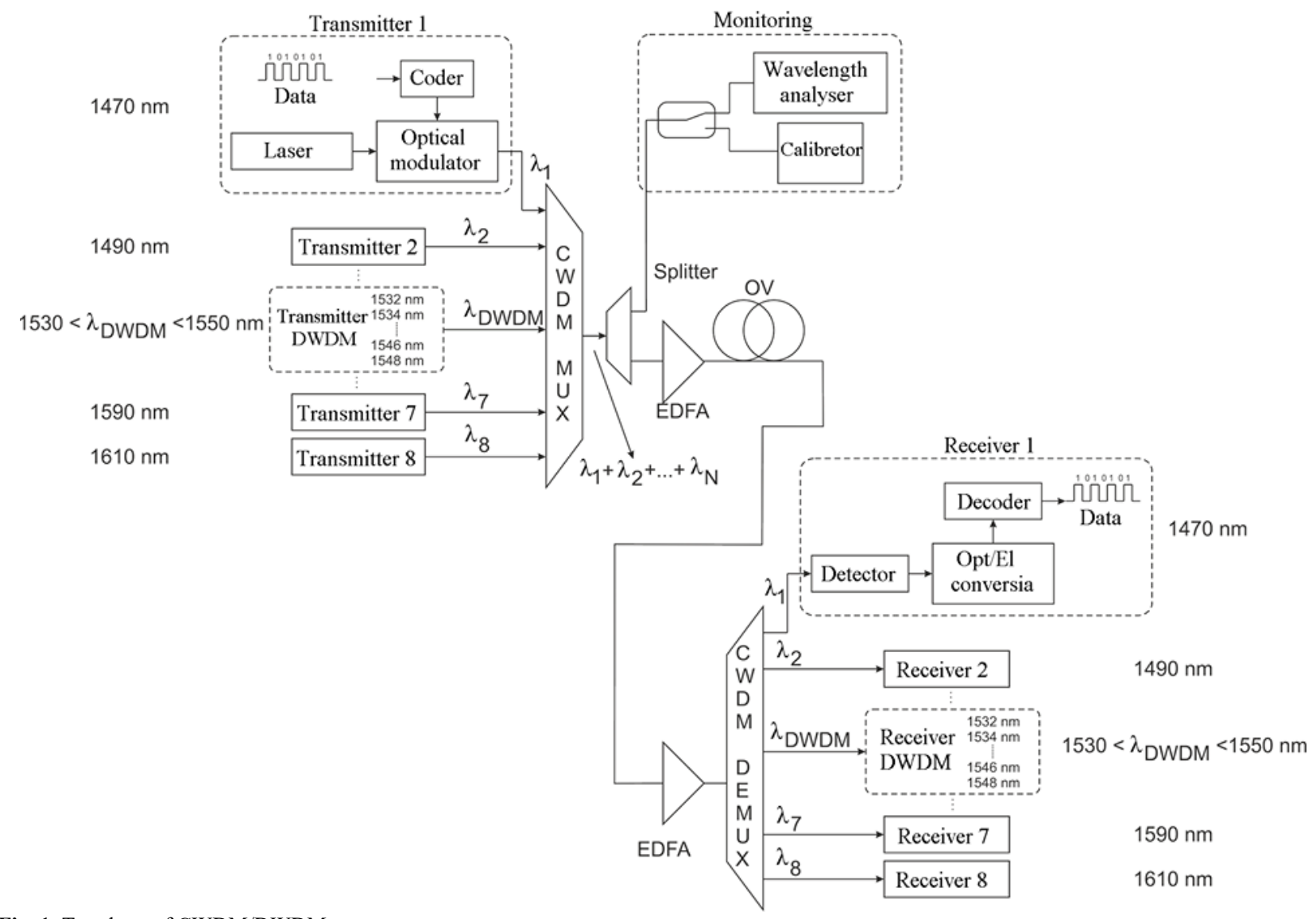

Fig. 1. Topology of CWDM/DWDM 
The DWDM system is integrated into the mentioned configuration connecting into the existing CWDM system according to the recommendation ITU T G.694.1. In this case, the increase in the number of channels happens at the same spectrum of wavelengths. In Figure 1 the topology of a CWDM/DWDM system is used to compare the BER of the output.

\section{Bit Error Rate}

Every optical network needs to be tested before being introduced to public service. The testing identifies whether the optical network is correctly connected and whether it is sufficient for a reliable and faultless transfer of data. For telecommunication data transfers the BER value represents the percentage of faulty bits to its total number of received bits at the input of the receiver of that transfer route [27]. In brief, BER is the figure regarding how the data is needed to be resent due to possible faults occurring.

\section{Creation of the eye diagram}

The eye diagram is the most employed tool (analysis) in communications to evaluate the received signal. By looking at the output diagram individual faults can be identified. The diagram is used for the evaluation of the optical line of some system (in our case the individual lines of DWDM). Some terms - like Q-factor, bit error rate or SNR (Signal to Noise Ratio) - are closely related to the eye diagram [16], [28]. The ideal shape of the eye $\left(10^{-40}\right)$ should contain the transmitted " 1 " and " 0 ". In Figure 2 an ideal eye diagram can be seen.

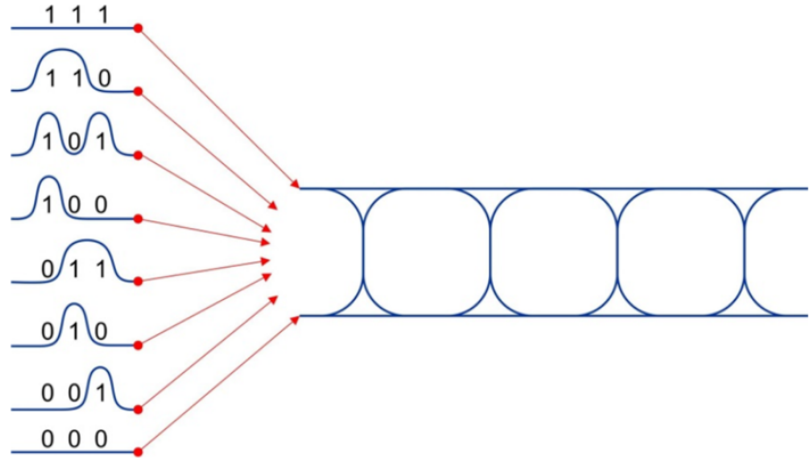

Fig. 2. Creation of the ideal eye diagram

\section{BER and related $Q$ factor}

BER depreciates in the case where the decisive level extends beyond the interference - which then results in an incorrect interpretation of received optical impulses. In practice, the optical line is delivered to the network provider with a complete documentation and with the individual values of BER evaluating individual lines (BER representing the criteria of quality of the line) [29-30]. BER is calculated based on its number of acknowledged faults received in that particular optical signal:

$$
B E R=\frac{N_{E}}{N_{A}},
$$

where $N_{E}$ represents all faulty bits and $N_{A}$ represents all received bits. In Figure 3 the density of BER expectancy is shown.

BER is closely related to Q-factor which can be calculated by minusing $\gamma_{o p t}$, which represents the optimal value of the middle level of logical " $O$ " and logical " $I$ ":
$Q=\frac{\mu_{1}-\gamma_{o p t}}{\sigma_{1}}=\frac{\gamma_{o p t}-\mu_{0}}{\sigma_{0}}=\frac{\mu_{1}-\mu_{0}}{\sigma_{1}+\sigma_{0}}$,

where it applies that:

$$
\gamma_{o p t}=\frac{\mu_{1} \sigma_{0}-\mu_{0} \sigma_{1}}{\sigma_{0}+\sigma_{1}}
$$

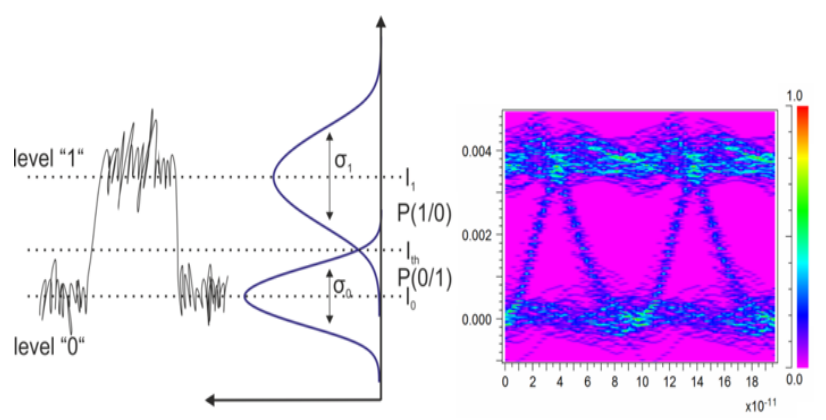

Fig. 3. The eye diagram with divided density of expectancy

In Figure 2 the expected values of BER $P(\mu(t)>$ $\left.\gamma_{\text {opt }} \mid \mu_{0}\right) / P\left(\mu(t)<\gamma_{\text {opt }} \mid \mu_{0}\right)$ indicated the real values when the particular expectation $\mu(t)$ is greater/lesser than the optimal value $\gamma_{\text {opt }}$ or the middle value of the level logic $, 1 “ \%, 0 "$. It indicates that the specific areas overlap and there is problem in differentiating whether a " $l$ " or " 0 " was received [16], [17] and [22]. This problem of differentiating what was received at/in output could be defined by equations separate for " $l$ " and separate for " $O$ ":

$$
\begin{aligned}
& P(1 \mid 0)=\frac{1}{\sigma_{0} \sqrt{2 \pi}} \int_{\gamma_{o p t}}^{\infty} e^{-\frac{1}{2}\left(\frac{\mu-\mu_{0}}{\sigma_{0}}\right)} d \mu=\frac{1}{2} \operatorname{erfc}\left(\frac{\gamma_{o p t}-\mu_{0}}{\sigma_{0} \sqrt{2}}\right), \\
& P(0 \mid 1)=\frac{1}{\sigma_{1} \sqrt{2 \pi}} \int_{\gamma_{o p t}}^{\infty} e^{-\frac{1}{2}\left(\frac{\mu-\mu_{1}}{\sigma_{1}}\right)} d \mu=\frac{1}{2} \operatorname{erfc}\left(\frac{\mu_{1}-\gamma_{o p t}}{\sigma_{1} \sqrt{2}}\right),
\end{aligned}
$$

where BER equals:

$$
\begin{aligned}
& B E R=\frac{1}{2}[P(1 \mid 0)+P(0 \mid 1)]= \\
& =\frac{1}{4}\left[\operatorname{erfc}\left(\frac{\gamma_{o p t}-\mu_{0}}{\sigma_{0} \sqrt{2}}\right)+\operatorname{erfc}\left(\frac{\mu_{1}-\gamma_{o p t}}{\sigma_{1} \sqrt{2}}\right)\right], \\
& B E R=\frac{1}{2} \operatorname{erfc}\left(\frac{Q}{\sqrt{2}}\right) \approx \frac{e^{\left(-\frac{Q^{2}}{2}\right)}}{Q \sqrt{2 \pi}} .
\end{aligned}
$$

BER is also closely connected to SNR, which could be expressed as a ratio of a signal's power $\left(P_{S}\right)$ to the ration of noise power $\left(P_{N}\right)$. The horizontal portrayal in Figure 3 shows SNR. It is applied that the lower the BER the greater the value of SNR:

$S N R=\frac{P_{S}}{P_{N}}$ 
In the case that the signal contains additional noise, the amplifier amplifies both segments. A situation is possible when the signal is unrecognisable from a high level of amplified noise. The correlation between BER and SNR could be defined as:

$$
B E R=\frac{1}{2} \operatorname{erfc}\left(\frac{S N R}{2}\right)
$$

When the bit error rate is small, it is more efficient to calculate Q-factor using OSNR as follows:

$$
Q_{d B}=20 \log \sqrt{O S N R} \sqrt{\frac{B_{0}}{B_{E}}}=\operatorname{OSNR}_{d B}+10 \log \frac{B_{0}}{B_{E}},
$$

where $B_{E}$ defines the electric bandwidth behind the receiver and $B_{0}$ defines the bandwidth reaching the detector. The noise figure NF (Noise Figure) usually increases by a spontaneous emission when employing EDFA. In the case that the ASE is examined (Amplified Spontaneous Emission) in relation to the signal, the OSNR could be defined as:

$$
O S N R=\frac{P_{I N}}{N F \cdot h \cdot f \cdot \Delta f},
$$

where $h$ is Planck constant $\left(6.626 \cdot 10^{-34}\right), N F$ is the noise figure of a particular EDFA, $P_{I N}$ defines the input power, $f$ is the frequency of radiation, $\Delta f$ is the bandwidth in which the $N F$ measurement took place. According to the equation (11) the total number of OSNR could be defined, where the lower index $i$ determines the grade of the particular system:

$$
\frac{1}{O S N R_{C E L K}}=\sum_{i} \frac{1}{O S N R_{i}}
$$

The equation (11) could be extended for the fully optical communication line by every EDFA compensating the attenuation of its preceding $\mathrm{OF}$, with $N$ being the number of EDFAs with identical gain used. Then OSNR will be defined as:

$$
\operatorname{OSNR}_{i}=\frac{P_{0}}{N F \cdot \Gamma \cdot h \cdot f \cdot \Delta f},
$$

where $P_{0}$ is defined as the output power of the multiplex used and $\Gamma$ is the attenuation of the travelled distance. According to the equation (12) the total value of OSNR can be calculated:

$$
\begin{aligned}
& \operatorname{OSNR}_{C E L K}=\frac{1}{\sum_{i=1}^{N} \frac{N F \cdot \Gamma \cdot h \cdot f \cdot \Delta f}{P_{0}}}= \\
& =\frac{1}{N \cdot \frac{N F \cdot \Gamma \cdot h \cdot f \cdot \Delta f}{P_{0}}}=\frac{P_{0}}{N F \cdot \Gamma \cdot h \cdot f \cdot \Delta f \cdot N}
\end{aligned}
$$

The equations (13) and (14) assumed that $N F$ and $\Gamma$ do not change. Using ROA the OSNR is defined for level $i$ as:

$$
O S N R_{i}=\frac{P_{I N(i)} \cdot G_{R A(i)}}{N F_{i} \cdot h \cdot f \cdot \Delta f}
$$

where $G_{R A}$ represents the agent raising OSNR when using ROA (raman Optical Amplifier). From the equation (14) it is obvious that the growing distance results in the decrease of OSNR, but only when EDFA is connected [16], [22]. If a reduction of the drop is needed, there is the option of using the Raman amplification which increases the input power of EDFA according to the provided equation (15). To simplify the matter, a 16-channel DWDM system was created with gaps of $50 \mathrm{GHz}$ [22]. This simulation was created in the program environment "Matlab", to emphasise the relation between BER and Q-factor. In Figure 4 shows the ideal curve for BER and its corresponding Q-factor with red points indicating the individual values for the particular optical lines [22]. The line with a speed of $40 \mathrm{Gbit}^{-1}{ }^{-1}$ is acceptable in the case of its Q-factor being of value of approximately 6 and BER being under the value of $10^{-09}$.

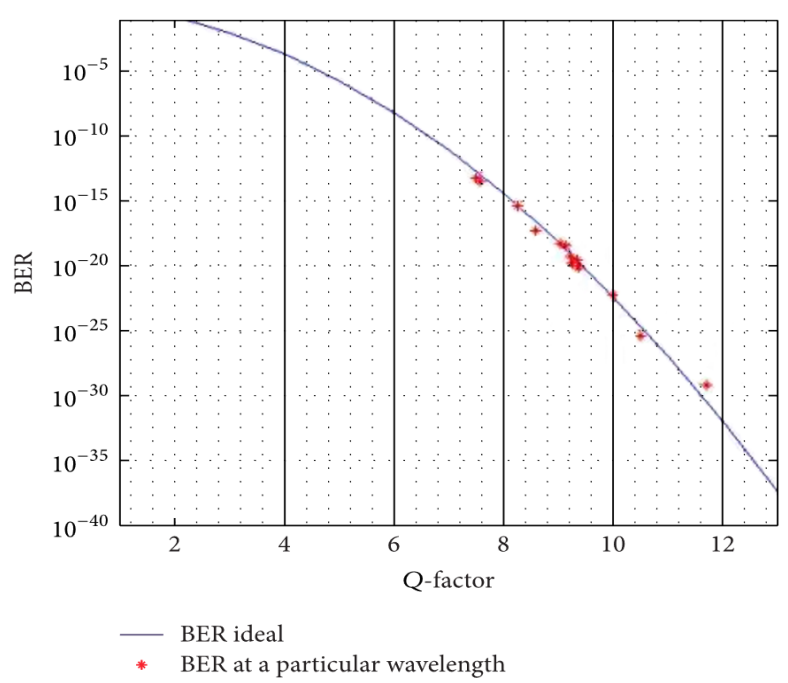

Fig. 4. Relation between BER and Q-factor (simulation in the environment „Matlab“) [22]

\section{Creation of CWDM/DWDM for comparison of BER in the output}

The whole constructed system is portrayed in Figure 1. It consists of three parts, which are: receiving, transferring and transmitting. The transmitting stage is created with 8 transmitting units from $1470 \mathrm{~nm}$ to $1610 \mathrm{~nm}$ with gaps of 20 $\mathrm{nm}$. Between the wavelengths of $1530 \mathrm{~nm}$ to $1550 \mathrm{~nm}, 10$ transmitting units with gaps of $2 \mathrm{~nm}$ were inserted. In Figure 5 can be seen the input spectrum of the signal.

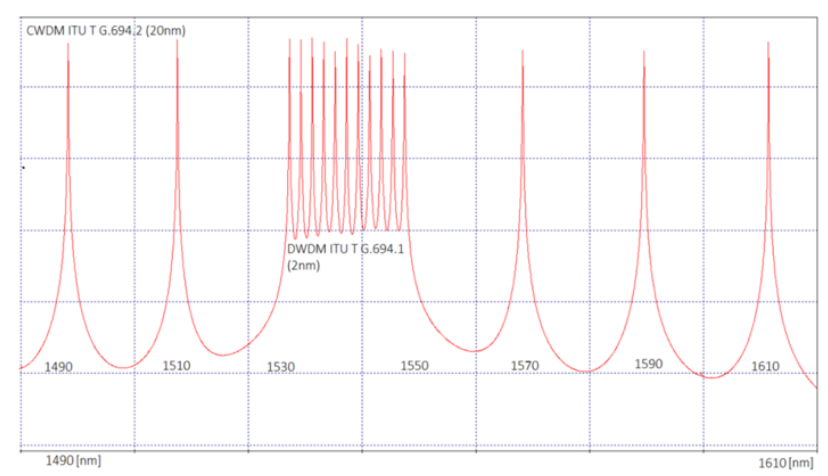

Fig. 5. Spectrum of CWDM/DWDM system 
Every transmitting unit contains 4 basic blocks which are: $\mathrm{CW}$ laser, modulator, coder and a data source. In our topology we used "MachZhender" type modulation, its power is set to the value of $1.03 \mathrm{~mW}$, and the bit speed of that channel is 10 Gbit.s $^{-1}$. In our case a CWDM system was created, with a transfer speed of $80 \mathrm{Gbit}^{-1} \mathrm{~s}^{-1}$ into which are inserted 10 channels with transfer speed of $100 \mathrm{Gbit.s}^{-1}$.After the transmitting units is placed the AWG multiplexor that joins the individual signals into a mutual optical fibre. A mathematical description of AWG and its use were defined in [18], [24]. The transfer part includes an optical splitter, OF and an amplifier of the EDFA type. The OF has an attenuation value of $0.3 \mathrm{~dB} \cdot \mathrm{km}^{-1}$ according to the recommendation G.652.D - additionally, the simulation ignored the Raman scattering effect and SBS (Stimulated Brillouin Scattering). The key component EDFA is set to a power value of $30 \mathrm{~mW}$ and it operates at $980 \mathrm{~nm}$.

The length of the Erbium-doped fibre was $14 \mathrm{~m}$ and it was chosen according to Figure 6 showing the best amplification was attained by precisely this length of fibre.

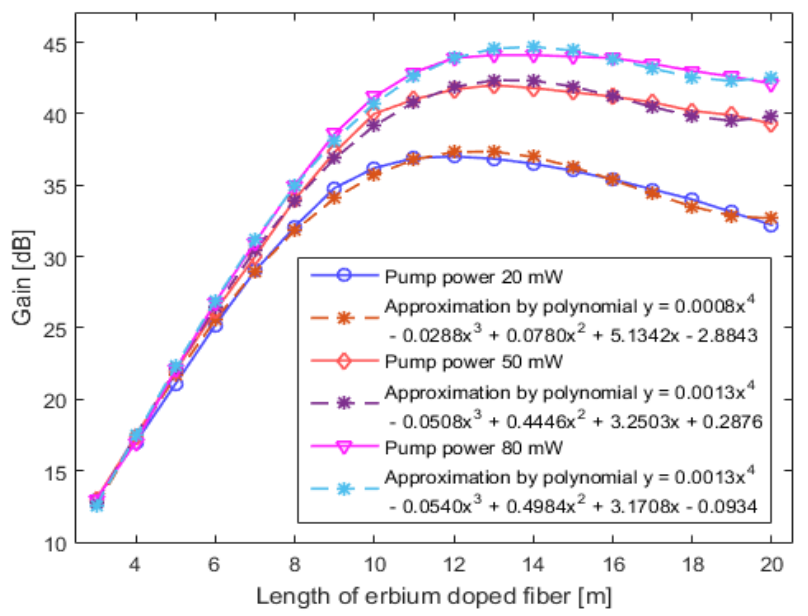

Fig. 6. Length of Erbium-doped fibre to EDFA gain

At the end of the transfer route is the demultiplexor where the separation of individual wavelengths happen. The receiving part consists of a filter set to the effectivity of 0.8 . It consequently leads to the transfer of the optical signal into its electrical form - and the output represents the individual data that were transmitted at the beginning of the line. For our designed system we measured one specific channel operating at a wavelength of $1540 \mathrm{~nm}$. To evaluate the quality of the line we utilised the measurement method based on the Monte Carlo type. The eye diagram with a bit speed of $10 \mathrm{Gbit}^{-1}$ after the distance of $90 \mathrm{~km}$ at a wavelength of $1540 \mathrm{~nm}$ is displayed in Figure 7.

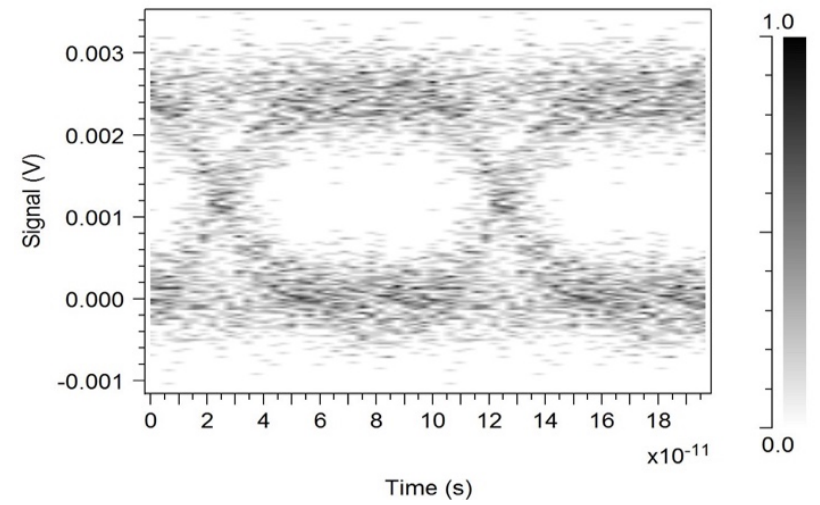

Fig. 7. Eye diagram for $1540 \mathrm{~nm}$ after $90 \mathrm{~km}$
The length of OF was chosen so the EDFA was able to amplify the signal to its best ability. Table 1 shows the values of BER for various lengths of OF.

Table 1. Length of OF in the optical system for the BER comparison.

\begin{tabular}{c|c|c|c|c}
\hline $\begin{array}{c}\text { Length } \\
\text { OF }(\boldsymbol{k m})\end{array}$ & $\boldsymbol{B E R}$ & $\boldsymbol{B E R}_{-} \min$ & $\boldsymbol{B E R}_{-} \max$ & $\boldsymbol{Q}^{2}(\boldsymbol{d B})$ \\
\hline 90 & $2.4785 \cdot 10^{-16}$ & $3.3362 \cdot 10^{-17}$ & $5.7894 \cdot 10^{-14}$ & 18.992 \\
95 & $7.5159 \cdot 10^{-14}$ & $5.8209 \cdot 10^{-15}$ & $8.7016 \cdot 10^{-13}$ & 17.369 \\
100 & $4.3659 \cdot 10^{-09}$ & $7.3663 \cdot 10^{-11}$ & $8.9892 \cdot 10^{-08}$ & 13.558 \\
105 & $1.4462 \cdot 10^{-05}$ & $6.2035 \cdot 10^{-06}$ & $3.2586 \cdot 10^{-05}$ & 12.427 \\
110 & $2.2262 \cdot 10^{-04}$ & $1.1152 \cdot 10^{-05}$ & $5.5522 \cdot 10^{-04}$ & 8.5585 \\
115 & $9.1415 \cdot 10^{-03}$ & $6.8273 \cdot 10^{-03}$ & $1.2116 \cdot 10^{-2}$ & 7.4576 \\
\hline
\end{tabular}

The increasing demand on transfer speed results in worsening of BER and a drop in Q-factor in the output. Figure 8 shows displayed drops of Q- factor depending on the distance of OF with increasing bit speed.

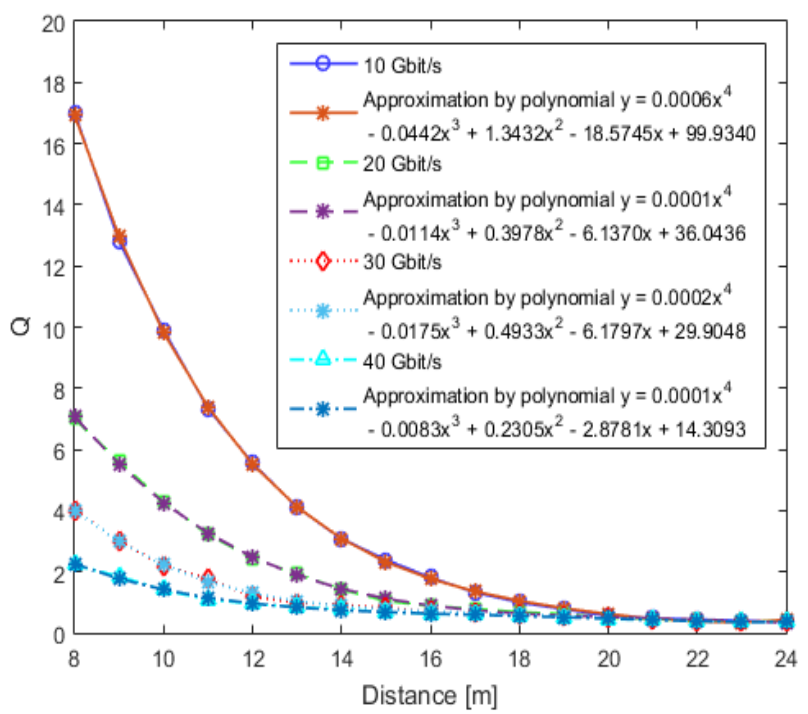

Fig. 8. Dependence of Q-factor on the length of OF at the change of bit speed

The aim of the system's construction was the appropriate application of EDFA in the transfer stage. According to Table 1 the most advantageous placement of EDFA is in the optical system after $90 \mathrm{~km}$. We created an optical loop where we applied EDFA and OF after $90 \mathrm{~km}$. The whole system was evaluated only for the wavelength of $1540 \mathrm{~nm}$. The optical loop was managed until BER had not dropped under the value of $10^{-9}$ - when it was not possible to distinguish the individual optical impulses in the output. Table 2 shows the final results of BER and Q-factor for a bit speed $10 \mathrm{Gbit}^{-1}{ }^{-1}$ for an optical line operating at $1540 \mathrm{~nm}$, when its 1 iteration equals the length of $90 \mathrm{~km}$.

Table 2. Final BER for various distances of the system.

\begin{tabular}{l|l|l|l|l}
\hline Iteration/km & $\boldsymbol{B E R}$ & $\boldsymbol{B E R \_ m i n}$ & $\boldsymbol{B E R \_ m a x}$ & $\boldsymbol{Q}^{2}(\boldsymbol{d B})$ \\
\hline $25 / 2250$ & $5.5581 \cdot 10^{-15}$ & $1.8978 \cdot 10^{-17}$ & $4.1448 \cdot 10^{-14}$ & 16.225 \\
$30 / 2700$ & $6.6656 \cdot 10^{-11}$ & $4.5441 \cdot 10^{-12}$ & $3.7065 \cdot 10^{-09}$ & 13.325 \\
$35 / 3150$ & $3.6589 \cdot 10^{-09}$ & $9.9898 \cdot 10^{-09}$ & $8.1284 \cdot 10^{-08}$ & 11.963 \\
$40 / 3600$ & $2.2252 \cdot 10^{-05}$ & $1.5889 \cdot 10^{-07}$ & $2.2278 \cdot 10^{-04}$ & 10.589 \\
\hline
\end{tabular}

In our proposed topology we theoretically did not exceed the distance of $3000 \mathrm{~km}$ while maintaining BER. To increase the distance we could have used the fibres of the type DCF (Dispersion Compensation Fibre). When creating the system with the optical loop we would use a standard $80 \mathrm{~km} \mathrm{SMF}$ 
fibre and directly behind we would place $20 \mathrm{~km}$ 's of DCF fibre. This would compensate for the dispersion in the output. With this topology of the optical loop we could possibly reach the distance of $4000 \mathrm{~km}$ in a way that would preserve BER in the output.

\section{Conclusion}

The aim of this article was the basic mathematical description of the bit error rate BER and also the possibility of fusing CWDM and DWDM systems to be implemented into one infrastructure. During the construction of the system, the EDFA was placed as In-Line so we would be able to reach the maximal possible length for this configuration. With the appropriate length of optical fibre (14 m, Fig.6) and by marinating the bit speed (10 Gbit. $\left.\mathrm{s}^{-1}\right)$ we could theoretically reach the distance of $3000 \mathrm{~km}$. The article also points to the necessity of using EDFA for distances up to $100 \mathrm{~km}$ so that the individual optical impulses are recognisable at the output. To breach a greater distance than $3000 \mathrm{~km}$, it would be advisable to also employ the fibres of the type DCF - in which case the theoretical distance increases to $4000 \mathrm{~km}$ (BER= $\left.2,842 \cdot 10^{-10}\right)$. The provider plays the key role in designing the system by determining the financial aspect of the system, the number of channels and the bit speed. It is necessary to consider that by condensing channels and increasing the speed, non-linear effects of the type XPM, SPM and FWM will occur in the optical power.

This is an Open Access article distributed under the terms of the Creative Commons Attribution License

\section{References}

[1] J. Papán, P. Segeč, M. Drozdová, L. Mikuš, M. Moravčík and J. Hrabovský, "The IPFRR mechanism inspired by BIER algorithm," 2016 International Conference on Emerging eLearning Technologies and Applications (ICETA), Vysoke Tatry, 2016, pp. 257-262, doi: 10.1109/ICETA.2016.7802053.

[2] J. Smiesko, J. Uramova, “Access node dimensioning for IPTV traffic using effective bandwidth",Komunikacie, vol. 14, no. 2, 2012, pp. 11-16.

[3] W. Steingartner, D. Radaković, F. Valkošák, Pavol Macko, "Some properties of coalgebras and their rôle in computer science", Journal of Applied Mathematics and Computational Mechanic, vol. 15, no. 4, 2016, pp. 145-156.

[4] V. Skorpil, R. Precechtel, "Training a neural network for a new node element design“, Przeglad Elektrotechniczny, vol. 89, no. 2B, 2013, pp. 187-192.

[5] U. J. Sindhi, D. S. Darji, A. A. Prajapati, R. K. Shah and R. B. Patel, "Gain optimization of EDFA for WDM system," 2017 International Conference on Communication and Signal Processing (ICCSP), Chennai, 2017, pp. 0087-0090, doi: 10.1109/ICCSP.2017.8286589.

[6] F. Certik and R. Roka, "Analysis of modulation techniques utilized in the optical transmission medium," 2012 ELEKTRO, Rajeck Teplice, 2012, pp. 30-35, doi: 10.1109/ELEKTRO.2012.6225603.

[7] P. Ivaniga, T. Ivaniga, J. Turan, L. Ovsenik, "Analysis of possibilities of increasing the spanned distance using EDFA and DRA in DWDM system“, Komunikacie, vol. 19, no. 3, 2017, pp.8895.

[8] T. Huszaník, J. Turán, and E. Ovseník, "Comparative analysis of optical IQ modulation in four-channel DWDM system in the presence of fiber nonlinearities, " in Proceedings of the 2018 19th International Carpathian Control Conference (ICCC), pp. 468-473, Szilvasvarad, Hungary, May 2018

[9] K. Bachrata, "Effective bandwidth for deterministic networks", Komunikacie, vol. 1, no.4, 2003, pp. 78-82.

[10] T. Huszaník, J. Turán, and L. Ovseník, "Impact of the optical fiber nonlinear phenomenon on the 16-channel DWDM OC-768 long-haul link," Elektrotechniski Vestnik, vol. 85, no. 5, pp. 255-262, 2018

[11]J. Smieško, "IP Network Management of Source for IP Traffics", Scientific Papers of the University of Pardubice, Series D, Faculty of Economics \& Administration, vol. 21, no. 32, 2014, pp. 109-117.

[12] J. Papán, M. Drozdová, P. Segeč, L. Mikuš and J. Hrabovský, "The new PIM-SM IPFRR mechanism," 2015 13th International Conference on Emerging eLearning Technologies and Applications (ICETA), Stary Smokovec, 2015, pp. 1-7, doi: 10.1109/ICETA.2015.7558504.

[13]Z. Bosternak, R. Róka, "Bandwidth Scheduling Methods for the Upstream Traffic in Passive Optical Networks", Przeglad Elektrotechniczny, vol. 94, no. 4, 2018, pp. 9-12, doi:10.15199/48.2018.04.03.

[14]J. Ruzbarsky, J. Turan and L. Ovsenik, "Effects act on transmitted signal in a fully optical fiber WDM systems," 2015 IEEE 13th International Scientific Conference on Informatics, Poprad, 2015, pp. 217-221, doi: 10.1109/Informatics.2015.7377835.
[15] Ch. Kumar, R. Goyal, "Performance Evaluation of Hybrid Optical Amplifiers for Super Dense Wavelength Division Multiplexing System with $25 \mathrm{GHz}$ Channel Spacing“, Journal of Nanoelectronics and Optoelectronics, vol. 13, no. 2, 2018, pp. 278-280.

[16]P. Ivaniga, T. Ivaniga, "Comparison of DPSK and RZ-DPSK Modulations in Optical Channel with Speed of 10 Gbps", Journal of Information and Organizational Sciences, vol. 41, no. 2, 2017, pp. 185-196.

[17] S. Sharma and S. Mohan, "Countering the gain behavior of Erbium Doped Fiber Amplifiers: A cross layer approach," 2013 IEEE International Conference on Advanced Networks and Telecommunications Systems (ANTS), Kattankulathur, 2013, pp. 1-6, doi: 10.1109/ANTS.2013.6802885.

[18]A. Abdullaev, J. Turan, "Survey of the problems and solutions of arrayed waveguide gratings used in the optical networks", Acta Electrotechnica et Informatica, vol. 14, no. 3, 2014, pp. 49-53, doi: 10.15546/aeei-2014-0029.

[19]A. Kaur, J. Singh, "Measurement of ASE in an in-line EDFA", International Journal of Advanced Research in Computer Science and Electronics Engineering, vol. 1, no. 7, 2012, pp. 190-198.

[20]D. Malik, G. Kaushik, A. Wason, “ Performance Evaluation of Optical Amplifiers for High-Speed Optical Networks“, Journal of Optical Communications, vol. 0, , pp.1-7, doi.org/10.1515/joc-20170133.

[21]P. Liptai, B. Dolník, M. Pavlík, J. Zbojovský, M. Špes, “Check measurements of magnetic flux density: Equipment design and the determination of the confidence interval for EFA 300 measuring devices“, Measurement, vol. 111, 2017, pp. 51-59.

[22]D. Zraková, M. Kubina, and G. Koman, "Influence of informationcommunication system to reputation management of a company," Procedia Engineering, vol. 192, pp. 1000-1005, 2017

[23] O. Kovac, P. Lukacs, and I. Gladisova, "Textures classification based on DWT," in Proceedings of the 2018 28th International Conference Radioelektronika (RADIOELEKTRONIKA), pp. 1-5, Prague, Czechia, April 2018.

[24] T. Ivaniga, J. Turan, L. Ovsenik, "Verification of the SPM Impact in DWDM System Using AWG Multiplexer / Demultiplexer", Acta Electrotechnica et Informatica, vol. 17, no. 1, 2017, pp. 17-22, doi: 10.15546/aeei-2014-0029.

[25] T. Kovacikova, P. Segec, and M. Kubina, "IMS in the Next Generation Network," in Proceedings of the 11th WSEAS International Conference on Communications, pp. 45-50, Agios Nikolaos, Crete Island, Greece, July 2007

[26] T. Ivaniga and P. Ivaniga, "Suppression of Nonlinear XPM Phenomenon by Selection of Appropriate Transmit Power Levels in the DWDM System," International Journal of Optics, vol. 2019, Article ID 9357949, pp. 1-8, 2019

[27]P. Ivaniga, T. Ivaniga, "10 Gbps optical line using EDFA for long distance lines“, Przeglad Elektrotechniczny, vol. 93, no. 3, 2017, pp. 193-196.

[28]H. Nain, U. Jadon and V. Mishra, "Evaluation and analysis of nonlinear effect in WDM optical network," 2016 IEEE International Conference on Recent Trends in Electronics, Information \& 
Tomáš Ivaniga and Petr Ivaniga/Journal of Engineering Science and Technology Review 12 (5) (2019) 1 - 7

Communication Technology (RTEICT), Bangalore, 2016, pp. 36-39, doi: 10.1109/RTEICT.2016.7807777

[29] L'. Mikuš, "Evaluations of the error rate in backbone networks", Elektrorevue, vol. 12, no. 2, 2010, pp. 1-6.
[30]D. Káčik and P. Tatar, "Modal interferometer based on double cladding photonic crystal fiber for refractive index measurement by equalisation wavelength," 2012 ELEKTRO, Rajeck Teplice, 2012, pp. 500-503. doi: 10.1109/ELEKTRO.2012.6225674 